\title{
Tax policies and entrepreneurship sustainability in Ondo State, Nigeria
}

\author{
Foluso Olugbenga Aribaba ${ }^{1}$, Rotimi Oladele ${ }^{1}$, Abdul-Lateef Olamide Ahmodu² ${ }^{*}$ (D) and Saliu Adesina Yusuff ${ }^{2}$
}

\author{
* Correspondence: \\ ahmoduolamidelateef10@gmail. \\ com; lateef.ahmodu@wesleyuni.edu. \\ ng \\ ${ }^{2}$ Department of Management \\ Sciences, College of Social and \\ Management Sciences, Wesley \\ University, Ondo P.M.B 507, Nigeria \\ Full list of author information is \\ available at the end of the article
}

\begin{abstract}
The study examines the effect of tax policies on the survival of entrepreneurship in Ondo State, Nigeria. The study employed survey research design with the population of 18 local government areas. The study adopted multi-stage sampling techniques to select the sample size of nine local government areas that have duly registered small and medium enterprises (SMEs) under Small and Medium-Scale Enterprise Development Agency of Nigeria (SMEDAN) in Ondo State. Structured questionnaire was administered and returned by the respondents. Data collected was estimated using ordered logistic regression to test the hypotheses formulated. The study revealed that the three explanatory variables (multiple taxation, tax rates, and tax incentives) accounted for $43 \%$ of the variability of SMEs sustainability in Ondo State with a $p$ value $<0.05, a=0.0029$. It also revealed that there was a negative significant effect between multiple taxation and sustainability of entrepreneurship; while tax rates and tax incentives have a positive relationship on entrepreneurship sustainability. Based on these findings, the study therefore recommends that for government to truncate unemployment rates that resulted to chronic poverty, banditry, kidnapping, and other social vices in the state, it is imperative that a favorable tax regime shall be provided which will encourage entrepreneurship sustainability and reduces social vises. This will not only enliven existing ones but also inspire the emergence of new ones. Friendly tax regime would engender voluntary compliance amongst the entrepreneurs in the long run with resultant tax yield.
\end{abstract}

Keywords: Entrepreneurships, Sustainability, Multiple taxation, Tax incentives, Tax rate, Tax policy

\section{Introduction}

Entrepreneurship as a proxy to small and medium enterprises (SMEs) sustainability in Nigeria has recently received considerable attention not only because of their entrepreneurial ability but also to create job opportunities. This will perpetually reduce the unemployed population but the perceived tendency to influence the economic growth of the state; increase per capital income, capital formation, and boost government tax revenue in the long run (Muritala, Awolasa, and Bako, 2012). An entrepreneur utilizes local materials thereby creating enabling market for local products in the country. A substantial number of business entities most especially the (SMEs) had failed because of their inability to sustain prevailing teething challenges some of them faced in their environment (Vasak, 2008;

(c) The Author(s). 2019 Open Access This article is distributed under the terms of the Creative Commons Attribution 4.0 International License (http://creativecommons.org/licenses/by/4.0/), which permits unrestricted use, distribution, and reproduction in any medium, provided you give appropriate credit to the original author(s) and the source, provide a link to the Creative Commons license, and indicate if changes were made. 
Olawale and Gariwe, 2010). It is worrisome because a larger portion of these problems were self-inflicted either by failure on the part of the government, the entrepreneurs themselves, or the business environment they operate. One of these challenges was the tax policies of the government that flagged the complicated and unfriendly economy of the country (Eftekhari, 2009). This has been evinced in incessant multiple taxation, high tax rates, and poor tax incentives which resulted to tax burdens.

Although, Ariyo (2005) affirmed that tax revenue is one of the avenues through which governments raise money for the purpose of providing infrastructures, social amenities, and catering for recurrent expenditure for developmental purposes. Musgrave (1984) stated that excise guidelines should remain structured in a way that would minimize direct interference with economic decisions of the state so as to expand and sustain such decisions. Excessive tax imposition shall be minimized to encourage compliance, most especially among upcoming businesses (Shahrodi, 2010). According to Weichendreder (2007), a good tax system should be the one that will allow efficient and effective tax administration understandable to the taxpayers. Taxes as an instrument of control within the economy should be judiciously used to achieve economic goals. These will not impede entrepreneurial sustainability after all the contributions of SMEs that are enormous could not be underestimated (International Tax Dialogue, 2007).

Myriad of studies have identified several factors influencing entrepreneurship sustainability in Nigeria but deviate from investigating the effect of government tax policies on the survival of SMEs. Determinants of entrepreneurial survival vary from one location to another in Nigeria. As such, this study examined the degree of connection between tax policies (that is, multiple taxations, tax rates, and tax incentives) and sustainability of entrepreneurs in Ondo State as a precursor to the sustainable growth of SMEs in Nigeria.

Small and medium enterprises (SMEs) have not really performed up to expectation as it has not been able to play a vital role in the creation of adequate wealth required of them; to create a certain level of employment and contribute significantly to gross domestic product (GDP) of Nigeria. Studies have attributed the incessant loss of jobs that worsening the existing rise of the pathetic employment situation in Nigeria to the constant failure of entrepreneurs (Fatai, 2011). This has however constituted a source of panic to the government at all levels as findings revealed that the prevalence of insecurity, banditry, insurgencies, and poverty that is ravaging the country also affect the sustainability of SMEs.

Entrepreneurial sustainability should be promoted and accorded priority but in Nigeria, the case is reversed. Entrepreneurial development has been bedeviled with several challenges ranging from government self-induced bogus tax regime, unfriendly economic structures, and environmental constraints in Nigeria (Acs and Virgill, 2010; Igbinovia and Okoye, 2017). The most dishearten tax system was inimical with strict tax policy that was repelling the existing and intending entrepreneurs. Studies affirmed that in Nigeria, over $80 \%$ of entrepreneurs collapse or fail on or before the end of 5 years of existence due to unfavorable business environment (Ocheni and Gemade, 2015). Taxes collections are deemed vital source of income to enable government to execute developmental projects and improve the living standards of the citizenry. 
Nevertheless, punitive tax regime with tax policies that focuses on the plight of Multinational Corporations tax issues and leaving those affecting SMEs has been a source of challenge to entrepreneurship (Babatunde, 2014). As stressed by Ariyo (2005), and Olawale and Gariwe (2010), Nigerian tax system has been characterized with multiple taxation, high tax rates, bogus tax regulations, poor tax incentives, and lack of low concern about entrepreneurs but for multinational. Other problems of entrepreneurship like insufficient funds, poor technical and administrative skills, environmental effects and government code of practice in emerging economies like Nigeria; multiple taxation, differential tax rate with an unclearly defined tax incentives that have been reported and deadly cankerworm eating deep into the working capital of Nigerian entrepreneurs thereby influencing their business growth.

As such, the study focused on these objectives to examine the effect at which multiple taxation, tax rates, and tax incentives have on entrepreneurship sustainability with respect to Ondo State, Nigeria. Ondo State is one of the states that have poor entrepreneurship clusters in the southwestern region of the country. This is a precursor to enhance the sustainability of entrepreneurship for economic growth.

\section{Conceptual and empirical review}

\section{Concept of tax policy and entrepreneurship sustainability}

Farzbod (2000) conceptualized the sway of tax policy on SMEs businesses and unveiled the issues weighing against SMEs tax passivity include exorbitant tax rates and multiple taxation, low tax incentives, low efficiency, and also that a tax system executed poorly usually leads to low productivity. The study recommended a reviewed tax system best capable of sustaining SMEs. Similarly, Shahrodi (2010) also conceptualized the impact of the tax system on the growth of entrepreneurs and found that the tax policy of the government on SMEs has not in any form favor the growth of SMEs. Tomlin (2008) viewed tax policy on the growth of SMEs; the study found that a complex tax and clumsy regime with correspondent multiple taxation put under undue pressures on entrepreneurship. In as much, the compliance requirement; the rate of acquiescence and levy payable is equal for both small and large companies under the regular system of taxation. International Tax Dialogue (2007) conceded a study on the impact of regulatory environment on the SMEs. The study affirmed that SMEs have to carry out its operations most times in an environment full of a series of regulations. Environment with a retinue of regulatory agencies and multiple taxes and also have to deal with legions of agencies at great cost. A conducive tax environment to enable SMEs to meet possible tax obligations was however recommended.

\section{Multiple taxes}

A situation whereby similar asset or action is burdened many periods by dissimilar jurisdiction within the same federal unit is tagged multiple taxation. Multiple taxation arise where the three tiers of government, namely, federal, state, and local authorities tax the same assets, properties, income, or the same wealth within the 
same federal system. Pitigala and Hope (2011) confirmed that literature even named multiple taxation to include 'nuisance taxes' because they can increase tax burdens by unnecessarily heightening the cost of administrative to both the government and businesses. Appreciable development in the world economy has been attributed to the activities of small and medium scale enterprises (SMEs), most especially in emerging economies like Nigeria. Pitigala and Hoppe (2011) reaffirmed that the Nigerian Federation comprises of three tiers of government namely the Federal Government, 36 states and 774 local government areas. Worst still the exact number of taxes levied on businesses seems to be vary significantly between states and local governments throughout Nigeria and businesses be subjected to as many as a 100 different taxes, charges, fees, and levies in some instance taxed for the same event or assets that are levied by the three tiers (Trade Policy Note, 2007).

\section{Tax rate}

The tax rate is the percentage payable as tax by taxpayers on profit and or economic transactions. Kirchler (2007) affirmed that it is somehow difficult to separate the impact of tax rates and income, especially when the variables changed at the same time in experimental studies. Jackson and Farzbod (2000) argued that the perceived fairness of the tax rate is more important than its absolute level. Determination of the fairness in taxation entails possession of thorough knowledge and correct interpretation of the tax law, and complex tax rate structures, such as progressive taxation which are not well understood most taxpayers who could hardly pay for the services of consultants. The desire of taxpayers' for progressive, flat, and regressive taxation is a function of the individual tax rates presented most especially when tax rates are depicted as an abstract concept or in concrete terms with a hypothetical illustration. (Roberts, Hite and Bradley, 1994). In the same vein, McCaffery and Baron (2004), with the aid of a structured questionnaire requested their respondents to reflect what they consider to be a fair tax rate for different amount of revenue. Urge for progressive taxation was stronger when the amount of taxes had to be indicated in absolute amounts. Further, information concerning the impact of tax rates could assist tax authorities to promote changes in tax policy in such a way that tax rate rises without reducing the degree of tax compliance (Kirchler, 2007). For the source of income, Boylan and Sprinkle (2001) affirmed in their study that respondents/taxpayers reacted to a marginal increase in tax rate with lower compliance.

\section{Tax incentives}

Klemm (2009), Gurtner and Christensen (2008) described tax inducements as parameters put in place by government through the tax authorities provide a more friendly or favorable tax treatment of certain activities and for some flagged sectors of the economy likened to what was approved to industries. With this arrangement, there would be an overall reduction in the tax rate or better still a generous depreciation program. Note that, those incentives applicable to all firms would not be considered tax incentives. Furthermore, Babatunde (2014) reiterated that tax incentives are one of the instruments deployed to encourage the acquisition of new technology or to enable the economy to benefit from. Incentives are tool for stimulation of consumption; incentive for encouraging research and development activities for the purpose of solving problems; 
and for the attainment of mass food production; improve social security. Tax incentives could be adopted to instill a desired economic culture of savings and investment as well as stimulating foreign exchange earnings (Gurtner and Christeinsen, 2008).

\section{Empirical review}

Adebisi and Gbegi (2013) establish that multiple taxation portends adverse influence on SMEs' existence, and that link amid SMEs' size and entrepreneurs' capacity to remit returns are highly momentous. Oboh, Yeye, and Isa (2013) conducted a study on the effect of manifold tax practices and taxpayers compliance attitudes in Nigeria. Correlation analysis revealed that multiple tax practices have a significant effect on taxpayers' compliance attitude, but the result revealed the attitude of Nigerians towards corruption, poor tax administration, and greed. Masud, Aliyu, and Gambo (2014) carried out a study on the effect of tax rate on tax compliance in Africa using cross-country data. African countries were the study population, upon which sample was selected using multi-stage approach. Data was analyzed with correlation analysis. Result revealed a significant negative correlation between tax rate and tax compliance and tax rate depict a negative impact on tax compliance. As such, the study suggested inasmuch the average tax rate is $29.1985 \%$ in Africa, countries with tax rates above average are advised to reduce their tax rate to improve tax compliance as well as encourage industrial and entrepreneurial growth.

Abdusalam, Almustapha, and El-Mande (2014) correlated tax rate with tax compliance in Africa using cross-country data. The study adopted multi-stage sampling approach. Results revealed that there is no positive and significant mutual relationship between tax rate and tax compliance while rate of tax also does not have a positive effect on tax compliance. The study recommended, in line with other studies, that any country experiencing serious tax violation is advised to cut her tax rate to the mean tax rate of $29.1985 \%$ to improve voluntary compliance.

Furthermore, Atawodi and Ojeka (2012) examined the impact of tax rates on SMEs using primary data obtained from the administration of questionnaire on the respondents. The study found that the choice of tax policy to adopt rest heavily on the use of one or more instruments which include the incentives to support start-up as well as the development of SMEs. Incentive could include special tax exemptions or tax holidays and reliefs for SMEs in form of the lowering tax rates. Chipeta (2002) conducted a study to show the impact of tax policy on tax rates with the aid of primary data sourced from administration of questionnaire on selected respondents. The study found that high rate of tax evasion by SMEs is as a result of high tax rates that increase the burden of the taxpayers most especially, the new entrepreneurs. Hence, the tendency to evade tax is higher. Government therefore is expected to revisit tax bias against SMEs by designing tax policies best capable of reducing entrepreneurial failures.

Igbinovia and Okoye (2017) examined the perception of some entrepreneurs in Benin City, Nigeria, with a view to finding out their stake on tax burden, tax incentives, and entrepreneurial development in Nigeria. A cross-sectional survey research design was employed and data were obtained from the responses of 140 respondents structured research questionnaire designed on a 5-point Likert attitudinal scale, reflecting various preferences and level of agreement with certain 
questions and assertions. Data was analyzed with the Spearman's rank correlation and the ordinary least square (OLS) regression techniques. It was revealed that a larger number of respondents confirmed that tax burden is a disincentive to entrepreneurial development having observed a negative significant relationship. Furthermore, the study confirmed does a positive but insignificant relationship exist between tax incentives and entrepreneurial development in Nigeria.

Feyitimi, Odelabu, Babatunde, and Obisesan (2016) investigated the impact of tax incentives on the growth and development of SMEs in Nigeria. Descriptive statistics was adopted using primary collected from the administration of questionnaire on respondents. Data collected was analyzed using ordinary least square regression. The study found a significant relationship between tax incentives and entrepreneurial growth. The study recommended friendly tax policy, tax holiday with better incentives to SMEs. Another study by Oriakhi and Osemwengie (2013) focused on tax incentives and revenue productivity of the Nigerian tax system covering 1981 to 2009 periods purposely to identify the short-run performance of various taxes using income elasticity of taxes and buoyancy of tax revenue. Secondary data obtained was analyzed using regression. The study reports an unsatisfactory level of total tax revenue productivity in the country.

\section{Methodology}

The study employed a survey research design method with the aid of administration of a structured questionnaire to seek the opinions of people attitudes and descriptions of respondents in the accomplishment of cause and effect relationship. The SMEs in 18 local government areas of Ondo State, Nigeria, is the population of this study. The sample size and sample technique used for this study were nine local government areas through simple random and quota sampling technique to cover the areas that have high entrepreneurial hub in the state. The rationales for selecting these entrepreneurs are found in the local government area that has manufacturing office in the state. It also focused on the areas that have higher number of the duly registered small and medium enterprises (SMEs) under SMEDAN in Akure in order to gain access to a good number of respondents. The findings and results of this study could be distorted if we fail to consider these 9 local government areas.

The instrument used was validated; Cronbach's Alpha was used to ascertain the reliability of the instrument, and the result shows the coefficient value of 0.921 reliability against 0.7 target. This shows that the instrument measured what it purported to measure. In addition, 252 copies of structured questionnaire were administered on the respondent being 28 copies in each local government area. Responses of 152 representing 60.32\% SMEs were returned. Base on various ownership and legal framework at various levels.

The SMEs selection covers small businesses like; small manufacturers/producers, fabricators, printing press, small internet providers, and registered service providers. This selection of SMEs was done by judgmental sampling to enable the researcher to obtain a fair representation of the population. statistical tool of frequency tables and percentages was used to assess and analyze data collected. The research hypothesis was tested using chi-square and Ordered Logistic Regression (Table 1). 
Table 1 Response rate

\begin{tabular}{lllll}
\hline S/N & Local government & Local government-HQ & Responses & $\%$ \\
\hline 1 & Owo & Owo & 15 & 10 \\
2 & Akoko North West & Ikare & 14 & 9 \\
3 & Idanre & Idanre & 12 & 8 \\
4 & Akure South & Akure & 21 & 14 \\
5 & Ese Odo & Igbekebo & 15 & 10 \\
6 & Akure North & lju/ltaogbolu & 23 & 15 \\
7 & Odigbo & Ore & 17 & 11 \\
8 & Okitipupa & Okitipupa & 18 & 12 \\
9 & Ondo West & Ondo & 17 & 11 \\
& Total & & 152 & 100 \\
\hline
\end{tabular}

Source: Authors' compilation, 2018.

\section{Model specification}

To ascertain the effect of tax policies on the sustainability of small and medium scale enterprises in Ondo State, Nigeria. This model was adopted although modifications were made to formulate the following equations. Therefore, the general model specification is represented as follows:

SSMEs $=f(M t, T r, T i)$

SSMES $=\alpha_{0}+\beta_{1} M t+\beta_{2} T r+\beta_{3} T i+U$

SSMEs is sustainability of small and medium enterprises

$\alpha$ is constant

$\beta$ is the beta coefficient (coefficient of the independent variable).

$M t$ is multiple taxes

$\operatorname{Tr}$ is tax rates

$T i$ is tax incentives

$U$ is the error term

\section{SMEs Business Sector}

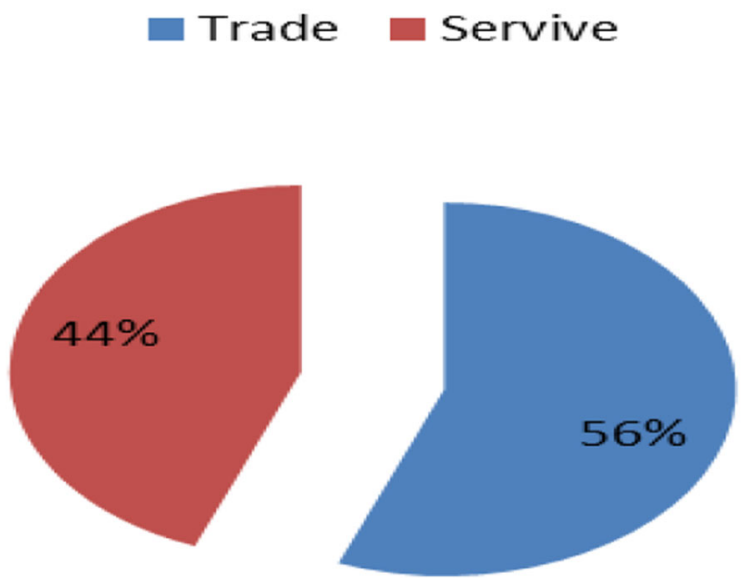

Fig. 1 SMEs Sub-sector 


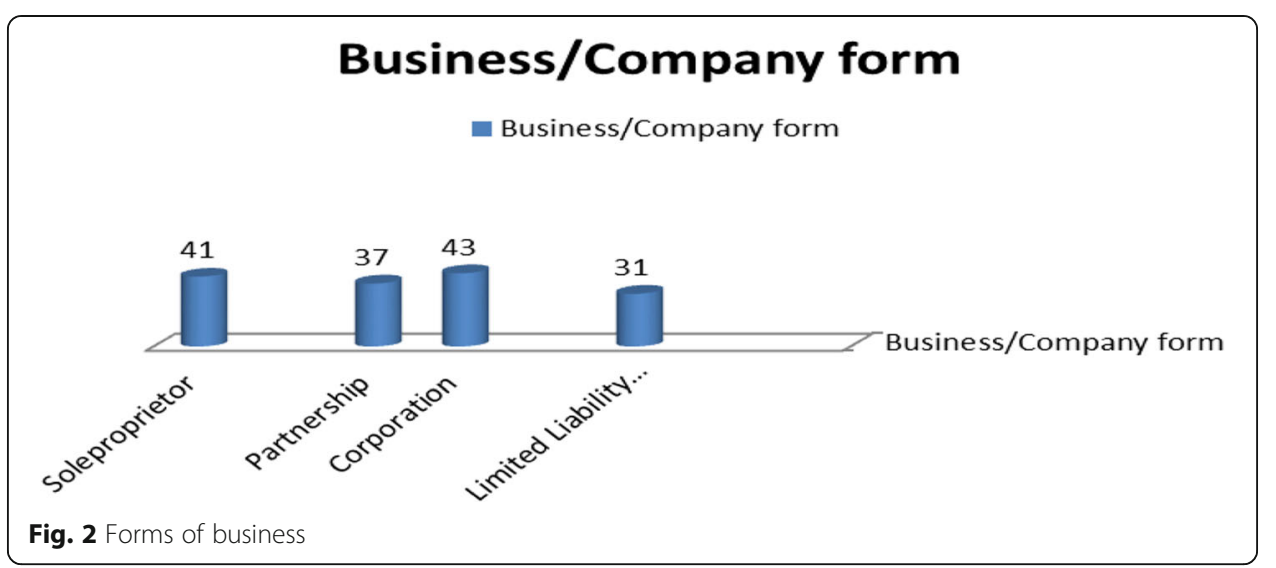

\section{Estimation results and discussion of findings}

This section presents analyses of the data employed as well as results of the analyses. The descriptive analysis of the data using chart was presented followed by the test of hypotheses.

Demographic representation of the respondents

As presented in Fig. 1, two sectors of SMEs were captures which are trade and service sectors. The former involved 67 (44\%) respondents while the latter comprised 85 (56\%) respondents. This implies that this investigation captured more entrepreneurs in service than in trade business. However, no existing studies to support the prevalence of more entrepreneurs in service than in trade business.

Regarding the forms of SMEs as pictured in Fig. 2, this study captured 41 sole proprietorship, 37 partnership, 43 corporate entities, and 31 limited liability businesses. The result unveiled that most of the respondents are entrepreneurs in corporate business followed by sole proprietors and entrepreneurs in partnership outfits.

The sampled SMEs had employees ranging from 1 to 5 and above 20. Most of the entities have between 1 and 5 (46) employees as shown in Fig. 3. The least number of employees was recorded within the range above 20 employees. This further confirms one of the attributes or definition of SMEs in term of the number of employees.

Also, concerning the age of the businesses, most of the SMEs have been in operation for a period between 1 and 5 years (37\%). Nevertheless, about $63 \%$ of the sampled

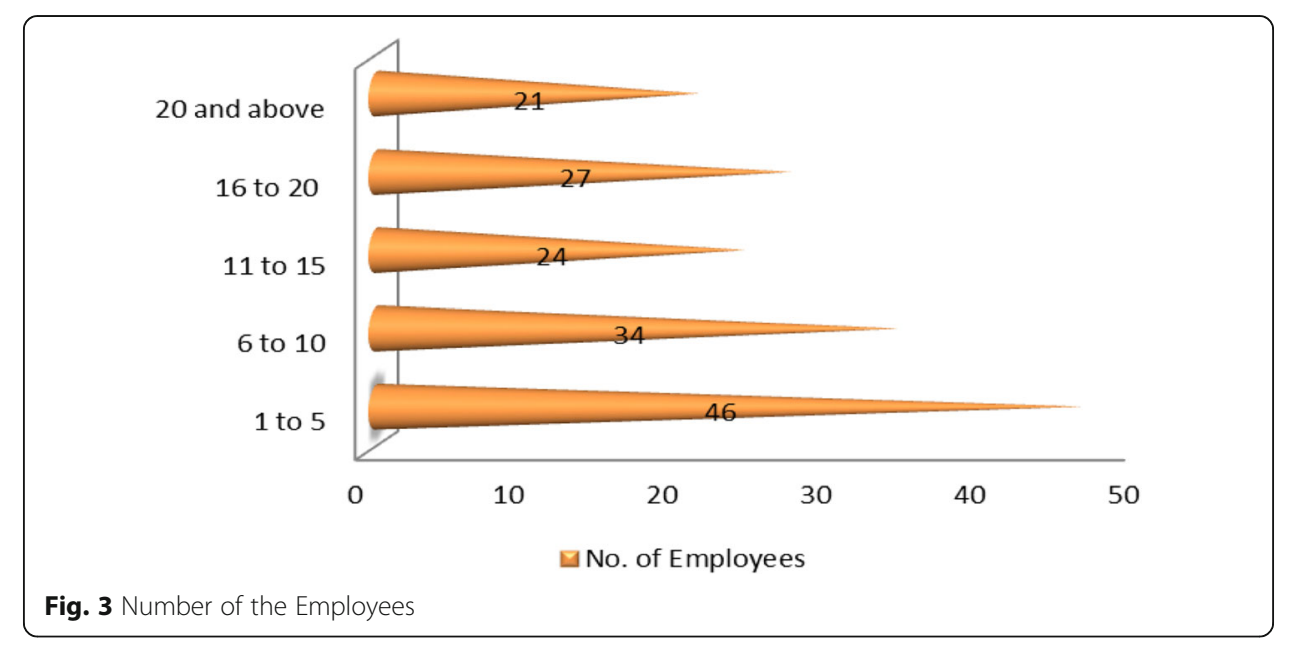




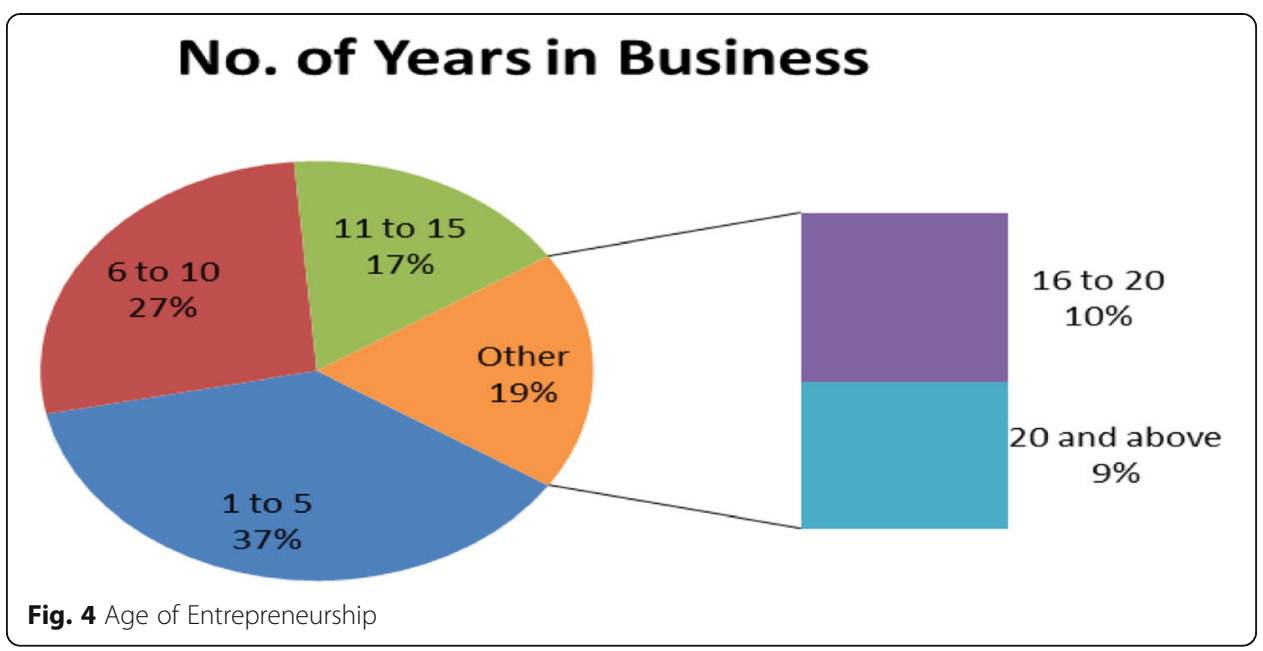

SMEs have been in operation for over 5 years. This suggests that most of the respondents came from SMEs that would have been experiencing the 'pros and cons' of the tax system in the state, ditto that of the federal (country) (Fig. 4).

Table 2 presents the result of Cronbach's alpha test on the validity and reliability of the research instrument used to elicit information from the respondents. The alpha coefficient for the summarized four items (one for dependent and other summarized three for each independent variables) is 0.7255 , suggesting that the items have relatively high internal consistency. (Note that a reliability coefficient of 0.70 or higher is considered "acceptable" in most social science research situations).

\section{Ordered logistic regression}

This model focuses on estimating the effect of multiple tax, tax rate, and tax incentive on the entrepreneurship sustainability in Ondo State using ordered logistic regression.

From the Table 3 above, the outcome of the ordered logistic regression of the pseudo $R^{2}$ value was 0.428 implying that approximately $43 \%$ of the predictive outcome in the SoSMEs in Ondo State was jointly explained by the multiple tax, tax rate, and tax incentive. The unexplained $57 \%$ of sustainability of SoSMEs is attributable to variables that were not captured in the model and are outside the scope of this study. The logistic regression chi-square value of 8.99 with the resultant $p$-value of 0.0029 demonstrated that the ordered logistic regression model is statistically significant at $5 \%$ level. The implication is that the ordered logistic regression model is valid and can be used for statistical inference. In testing study hypotheses, we provide specific analysis for each of the explanatory variables as follows.

Table 2 Cronbach's alpha test on the validity and reliability of the instrument

\begin{tabular}{ll}
\hline Alpha; Mt Tr Ti :SSME & Value \\
\hline Test scale = mean (unstandardized items) & \\
Average interitem covariance: & 0.1141124 \\
Number of items in the scale: & 4 \\
Scale reliability coefficient: & 0.7255 \\
\hline
\end{tabular}


Table 3 Ordered logistic regression model

\begin{tabular}{ll}
\hline Variables & Ordered logistic regression \\
\hline Multiple taxes $(\mathrm{Mt})$ & $-0.035(0.0095)$ \\
Tax rate $(\mathrm{Tr})$ & $0.38(0.22)$ \\
Tax incentives (Ti) & $0.80(0.23)$ \\
Pseudo ${ }^{2}$ & 0.428 \\
LR CHI2 & $8.99(0.029)^{*}$ \\
Observation & 152 \\
\hline
\end{tabular}

Note: ${ }^{*}$ is $5 \%$ level of significance. Values in bracket are $p$ values

For multiple taxes $(\mathrm{M} t)$ \{ordered logistic $=-0.035(\alpha=0.95>0.05)\}$ multiple tax portends negative and insignificant influence on the SoSME at $5 \%$ level. Hence, multiple tax has inverse relationship with SoSMEs and does not improve the model. This suggests that multiple tax, based on the submission of the sampled respondents, is not a tax policy feature that drives or determines the sustainability of entrepreneurship in Ondo State of Nigeria. That is, widespread of multiple tax system retards SoSMEs in the state but with no evidence of its significant effect. Thus, the prevalence of multiple tax policy features serves as setback to the sustainability of SMEs but this set back could not be established statistically. This finding is unique as it stands to contradict existing submissions by Oboh et al. (2013) that multiple taxes have a positive effect on the sustainable growth of entrepreneurship but in tandem with Adebisi and Gbegi (2013), and Ocheni and Gemade (2015) who obtained the negative influence of multiple tax on SMEs' survival.

Consistently with well embraced belief that multiple tax constitute a great burden to business growth, ditto sustainability of entrepreneurship, the inference of this finding is that probability that multiple tax will affect SoSMEs is not well pronounced in the sampled state which could have been perhaps because the tax system has been negotiated by the business owners' association or intervened by the government. Hence, multiple tax policy demonstrates no serious threat to the sustainability of SMEs in the Ondo State of Nigeria, thereby establishing the intent of ability-to-pay theory.

On the other hand, tax rate $(\mathrm{T} r)$ and tax incentives $(\mathrm{T} i)$ ordered logistic were $\{0.38(0.22)$ and $0.80(023)\}$ respectively. The $z$ value (Appendix 1$)$ revealed that each coefficient is different from zero. These coefficients showed that Tax rate and tax incentives have unidirectional (positive) relationship with sustainability of SMEs in Ondo State, Nigeria, but are statistically insignificant. This means that the two tax policy features have a positive impact but the probability of their influence on sustainability of SMEs is not significant at $5 \%$ level of significance. The implication is that, even though the findings suggest that as tax rate and tax incentive increases, the probability that it will lead to increase in the sustainability of SMEs cannot be established statistically contrary to the general belief of the entrepreneurs regarding the effect of the increased tax rate on business sustainability.

The implication is that tactful tax rate and entrepreneurial-friendly tax incentives demonstrate the likelihood of enhancing SMEs in Ondo State, Nigeria, thereby confirming ability-to-pay theory. Since tax rate is positively related to profitability 
according to Ezegwu and Akubo (2014) and that adequate compliance with tax policy rest on considerable tax rate as stressed by Atawodi and Ojeka (2012), tax rate should therefore be determined and reviewed as frequently as necessary to encourage not only sustainability of SMEs but also the establishment of more SMEs as opined by (Jeffery-Lloyd-Hanm BS: Income tax level and tax rate as determinant of tax compliance; An experimental examination, Unpublished) that tax incentives would encourage the start-up of new businesses.

\section{Conclusion and recommendation}

Complex tax regime has been observed; it is characterized by inconsistent tax rate with inherent multiple taxation that are inimical to sustainability of Nigerian entrepreneur. Out of the three variables investigated in this study, multiple tax portends a greater danger to sustainability of entrepreneurship in Ondo State if not tackled head-on (although, no statistical evidence to support this). Other two variables (tax rate and tax incentives) though depicted positive influence on the sustainability of entrepreneurship; the likelihood of its influence cannot be established statistically. Nevertheless, since the two tax policy features are directly related to sustainability of SMEs, then adequate control measure is required to ensure productive tax rate while tax incentive structured to reduce tax burden of SMEs should be prioritized.

Harmonization of taxes in the state and even at the three tiers of government is required. Besides, there is a need for constant review of tax policies most especially those that concern entrepreneurs. Tax rate should be kept at the utmost minimum at least to reduce the tax incidents. Tax incentives with tax holiday as well as other tax allowances should be expanded in favor of entrepreneurs. Creation of tax awareness and the incentives inherent among the SMEs by the Small and Medium Enterprises Development Agency of Nigeria (SMEDAN) and Bank of Industry (BOI) is recommended. This is because most entrepreneurs do not even know a few existing incentives nor engage in tax planning to reduce their tax liabilities. Unique natures of the findings of this study suggest a need for further investigation in other states of the country and in other similar economies.

\section{Appendix}

Table 4: Output of the Ordered Logistic Regression Analysis

\begin{tabular}{|c|c|c|c|c|c|c|}
\hline \multicolumn{7}{|c|}{ Number of Observations $=152$} \\
\hline \multicolumn{7}{|c|}{$\operatorname{LR} \operatorname{chi}^{2}(3)=8.99$} \\
\hline \multicolumn{7}{|c|}{ Prob $>$ chi $^{2}=0.0294$} \\
\hline \multicolumn{7}{|c|}{ Pseudo $R^{2}=0.428$} \\
\hline \multicolumn{7}{|c|}{ Log likelihood $=-100.65188$} \\
\hline SoSME & Coef. & Std. Err. & & z & $\mathbf{P}>\mathbf{z}$ & [95\% Conf-Interval] \\
\hline Mtx & -.0353818 & .6133525 & -0.06 & 0.953 & -1.237531 & 1.166767 \\
\hline Trt & .3827928 & .3151319 & 1.21 & 0.224 & -.2348544 & 1.00044 \\
\hline Tin & .8077932 & .6777960 & 1.19 & 0.233 & -.5206626 & 2.136249 \\
\hline /cut1 & 2.0319020 & .8262059 & & & .4125681 & 3.651236 \\
\hline
\end{tabular}




\section{Abbreviations}

BOI: Bank of Industry; F: Function; GDP: Gross domestic product; LR CHII': Logistic regression and chi-square; Mt: Multiple taxes; No: Number; OLS: Ordinary least square; SMEDAN: Small and Medium Enterprises Development Agency of Nigeria; SMEs: Small and medium enterprises; SSMEs: Sum of small and medium enterprises; Ti: Tax incentives; Tr: Tax rates; $\alpha$ : Constant; $\beta$ : Beta coefficient

\section{Acknowledgements}

We are greatly indebted to the participants of this study and the Management of Wesley University, Ondo and Federal University Oye-Ekiti, Nigeria, for allowing us to benefit from the provided enabling environment for this research and the assistance of librarian of the institutions for making available software to access the recent materials on this research.

\section{Authors' contributions}

AFO reviewed the literatures, designed the instrument for data collection, and fine-tuned the title of the research. He also contributed to the editorial work of the paper. OR contributed to the introduction of the study and fine tune the research topic for the current study. He also contributed to validate the instrument and drafted the conclusion and recommendations. AOL designed the methodology, coded the data, and analyze the data generated through SPSS. He also ran the plagiarism check through the Turnitin software and makes sure the article complies with the Journal of Global Entrepreneurship Research standard. YSA participated in interpreting the SPSS result outputs and discussed the findings. As an expert in International Business and Entrepreneurship, he makes sure that the article conforms to the scope of this journal. All authors read and approved the final manuscript.

\section{Funding}

There was no specific fund provided for this research by any funding agency. However, the lead author was encouraged to carry out this study which abetted us to hasten the research.

\section{Availability of data and materials}

The data collected for this study was analyzed during the current study and are available and can be submitted if required.

\section{Competing interests}

We hereby declared that this research work exposed us to so many ideas because of the number of authors involved. We are disclosing to you that there was a conflict of interest before the end of this research work which deprived some of our research team members from being part of this research article. We also disclose to you that our honorarium was contributed based on individual position which is also part of the decision that caused the removal of some of our research team members. The lead author was interested in this research work due to its implications to the Journal of Global Entrepreneurship Research and sees it as a method of mentoring the team on how to publish in an impactful journal. We finally declared that the activity in our various institutions does not encourage us to hasten the work and as a result, it almost caused conflict among the researchers from being delayed.

\section{Author details}

'Department of Accounting, Federal University, Oye-Ekiti, Nigeria. ${ }^{2}$ Department of Management Sciences, College of Social and Management Sciences, Wesley University, Ondo P.M.B 507, Nigeria.

Received: 18 March 2019 Accepted: 1 July 2019

\section{Published online: 26 August 2019}

\section{References}

Abdusalam, M., Almustapha, A. A., \& El-Mande, J. G. (2014). Tax rate and tax compliance in Africa. European Journal of Accounting, Auditing and Finance Research, 2(3), 22-30.

Acs, Z., \& Virgill, N. (2010). Entrepreneurship in developing countries. Foundations and Trends in Entrepreneurship, 5(7), 189-193.

Adebisi, J. F., \& Gbegi, D. O. (2013). Effect of multiple taxation on the performance of Small and Medium Scale Business Enterprises in Kogi State. Mediterrean Journal of Social Sciences, 4(6), 323-334.

Ariyo, D. (2005). Small firms are the backbone of the Nigeria Economy. Retrieved from http://www.africaeconomicanalysis. org/article.

Babatunde, S. A. (2014). Significance of tax incentives and infrastructural development on entrepreneurship in Nigeria. The Nigerian Accountant, 47(2), 4-13.

Boylan, S. J., \& Sprinkle, G. B. (2001). Experimental evidence on the relation between tax rates and compliance: The effect of earned vs. endowed income. The Journal of the American Taxation Association, 23(1), 7590.

Eftekhari, G. (2009). Tax policy and the Growth of SMEs, Implication for the Nigerian (pp. 78-89).

Ezegwu, C. I., \& Akubo, D. (2014). Analysis of the effect of high tax rate on profitability of corporate organizations in Nigeria. Mediterranean Journal of Social Sciences, 5(20), 310-321.

Farzbod, J. (2000). Investigation of the effective factors in the tax efficiency, Tehran: Governmental Management Training Center, $3(2), 112-130$.

Fatai, A. (2011). Small and medium scale enterprises in Nigeria, the problems and prospect. International Journal of Economic Development Research and Investment, 2(5), 102-125.

Feyitimi, O., Odelabu, A. O., Babatunde, L. A., \& Obisesan, S. O. (2016). Tax incentives and the growth of small and medium enterprises economy in developing economy, The Nigerian experience. European Journal of Research and Reflection, 4(2), 24-42.

Gurtner, B., \& Christensen, J. (2008). The race to the bottom: Incentives for new investment. Retrieved on from November 6 , 2016 http://www.taxjustice.net. 
Igbinovia, M. I., \& Okoye, E. (2017). Tax burden, tax incentives and entrepreneurial development. In 2017 International Conference on Entrepreneurships and Innovation for sustainable development Chapter 33.

International Tax Dialogue. (2007). Taxation of small and medium enterprises (pp. 56-67). Buenos Aires: Background Paper for the International Tax Dialogue Conference.

Kirchler, E. E. (2007). The economic psychology of tax behaviour. Cambridge: Cambridge University Press.

Klemm, A. (2009). Causes, benefits and risks of business incentives. IMF Working Paper WP/09/21Retrieved on November 6 , 2016 from http://www.imf.org

Masud, A., Aliyu, A., \& Gambo, J.E. (2014). Tax rate and tax compliance in Africa. European Journal of Accounting Auditing and Finance Research, 4(2), $22-40$.

McCaffery, E. J., \& Baron, J. (2004). Framing and taxation: evaluation of tax policies involving household composition. Journal of Economic Psychology, 25(6), 679-705.

Muritala, T., Awolaja, A., \& Bako, Y. (2012). Impact of Small and Medium Enterprises on economic growth and development. American Journal of Business and Management, 1(1), 18-22.

Musgrave, R. A., \& Peacock, A. I. (1984). Classics in the theory of public finance. New York: Macmillan.

Oboh, C. S., Yeye, O., \& Isa, E. F. (2013). Multiple tax practices and taxpayers' non-compliance attitude in Nigeria. International Research Journal of Finance and Economics, 103, 151-161.

Ocheni, S. I., \& Gemade, T. I. (2015). Effect of multiple taxation on the performance of Small and Medium Scale Businesses in Kogi State. Journal of Academic Research in Business and Social Review, 5(3), 345-364.

Olawale, F., \& Gariwe, D. (2010). Obstacles to the growth of new SMEs in South Africa: A principal component analysis approach. African Journal of Business Management, 45(5), 729-738.

Oriakhi, D. E., \& Osemwengie, P. K. (2013). Tax incentives and revenue productivity of the Nigeria tax system. International Journal of Development and Economic Sustainability, 1(1), 31-44.

Pitigala, N., \& Hoppe, M. (2011). Impact of multiple taxation on business competitiveness in Nigeria, Africa Trade Policy, 1(6), 1-25.

Roberts, M. L., Hite, P. A., \& Bradley, C. F. (1994). Understanding attitudes toward progressive taxation. Public Opinion Quarterly, 58(2), $165-190$.

Shahrodi, S. M. M. (2010). Investigation of the effective factors in the efficiency of tax system. Journal of Accounting and Taxation, 3(7), 917-928.

Tomlin, B. (2008). Clearing hurdles: Key reforms to make small business more successful. (Commentary No.264). Toronto, Ontario C.D.Howe Institute. Retrieved from www.cdhowe.org/pdf/commentary.

Vasak, S. (2008). Small, medium, large enterprises. USAID Business Climate Reform. Rretieved from http://pdf.Usaid.gov/pdf_ docs/PNADQ675.Pdf.

Weichendrieder, A.J. (2007). Survey on taxation of small and medium sized enterprises: draft report on responses to the questionnaire. Organization for Economic Co-operation and Development-Website-Retrieved-from http://www.oecd.org/ dataoecd/52/25/39597756

\section{Publisher's Note}

Springer Nature remains neutral with regard to jurisdictional claims in published maps and institutional affiliations.

\section{Submit your manuscript to a SpringerOpen ${ }^{\circ}$ journal and benefit from:}

- Convenient online submission

- Rigorous peer review

- Open access: articles freely available online

- High visibility within the field

- Retaining the copyright to your article

Submit your next manuscript at $\boldsymbol{s p r i n g e r o p e n . c o m ~}$ 